\title{
A Review on Implementation of Energy Audit
}

\author{
Kartik D. Ukhalkar \\ PG Student, Mechanical Engineering, Government College of Engineering, Amravati
}

Received on: 26 April,2021 Revised on: 29 May, 2021 Published on: 31 May 2021

\begin{abstract}
In any industrial, commercial and residential building, the top operating expenses is found to be energy. With the innovations in the electrical appliances, we can save a lot of energy. It is very important to conserve and manage energy as the energy requirement is more than production. An energy study of various sector of industrial, commercial and residential areas indicate that 5-20\% energy can be saved with energy auditing. Energy conserved is energy created. Energy audit plays an important role in finding opportunities to save energy and reduce electricity bills. Energy audit suggests ways to save energy consumption by some changes in the system with no negative output by the changes made. This paper focuses on the importance of energy auditing and the previous work done.
\end{abstract}

Keywords- energy audit, energy management, energy conservation, consumption.

\section{I - INTRODUCTION}

E nergy is one of the major factors for the development of any country as it decides the economic growth of the country. The energy consumption is increasing exponentially and to cope up with the requirement puts a tremendous load on the country's resources. The energy generation capacity of India, as of year 2021 is 379,130 MW which is increasing every year but so does the consumption. Almost $50 \%$ of the energy produced is from thermal power plant by consumption of coal. Energy conservation can be the best solution to deal with this situation of increasing energy demand.

An energy audit is a survey, analysis and inspection of the energy flow in the system to find the scope of energy conservation by implementing energy saving procedures without affecting the outputs of the system. It also includes submission of technical report containing recommendations for improving energy efficiency with investment cost required to execute the energy savings, cost saving analysis and action plan to be implement.

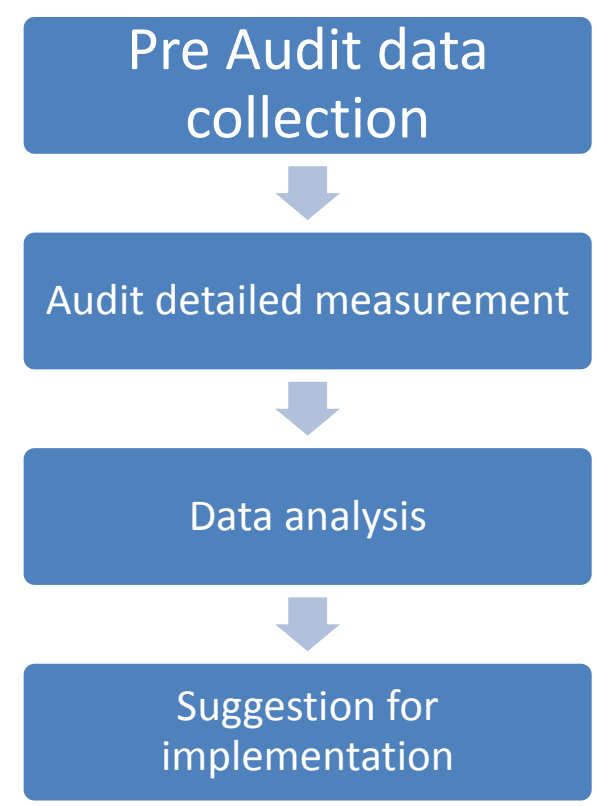

Fig. 1 -Process of energy audit

\section{II- NEED FOR ENERGY AUDIT}

In any industry, the top operating requirements are found to be energy, labor and materials. If one were to seek out the likelihood of energy saving in any of the three domains, energy will show the foremost scope and thus energy management constitutes a strategic area for cost reduction. Energy Audit will help to know more about 


\section{International Journal of Innovations in Engineering and Science, www.ijies.net}

the ways energy and fuel are utilized in any industry. It will also help in identifying the areas where waste can occur and where scope for improvement exists.

The Energy Audit would also provide a positive orientation to lower the energy cost, preventive maintenance and internal control programmes which are vital for production and utility activities. Such an audit program will help to stay specialize in variations which occur within the energy costs, availability and reliability of supply of energy, identify energy conservation technologies and retrofit for energy conservation equipment.

In general, Energy Audit is the formation of conservation ideas into realities, by applying feasible solutions which will help to lower the energy consumption in the organization without any negative output. Along with that it also lowers the energy consumption bills.

The primary objective of Energy Audit is to determine ways to reduce energy consumption or to lower operating costs. Energy Audit gives a "Reference point" for managing the use of energy. It also provides the basis for planning a more effective use of energy.

\section{III-ENERGY AUDIT METHODOLOGY}

The type of Energy Audit to be done depends upon:

- Type and function of industry

- Degree to which final audit is required

- Investment and Potential of cost reduction

Thus Energy Audit can be categorized into the following types.

1. Preliminary Energy Audit Methodology

Preliminary energy audit is a relatively easy exercise to:

- Scout energy consumption in the organization

- Find the scope for saving

- Identify the most likely areas for attention

- Identify areas of improvements/ savings

- Set a 'reference point'

- Identify areas for more detailed study

- Preliminary energy audit makes use of existing or easily obtained data

\section{Detailed Energy Audit Methodology}

A detailed energy audit provides implementation plan for an organization, as it evaluates all major energy using systems.

This type of audit gives the most accurate result for energy savings. Detailed energy audit methodology takes into consideration the effects of all systems which accounts for the energy use of all major equipment, and includes energy cost saving recommendations with calculations.

In a detailed audit, one of the important aspects is the energy balance. This is based on energy using systems, assumptions of current operating situation and by calculations of energy use. This estimated use is then checked by comparing with utility bill charges.

Detailed energy auditing is carried out in the following phases:

Phase I - Pre Audit Phase

Phase II - Audit Phase

Phase III - Post Audit Phase

\section{IV-LITERATURE REVIEW}

This review is based on the work done in Energy Audit in various sources. The literature shows the work done in the field of energy audit and management. The objective of this review is to identify the contribution of the researchers in the energy audit and their work done.

Anupama Gupta, Pallavi Verma and Richa Priyadarshani [1] in their work have discussed about the need of energy audit and types of energy audit methodology with the example of conducting an audit of fume exhaust system blower used in cold rolling mill. The fume exhaust blower had a motor of rating 3 phase $\mathrm{AC}$ induction motor of $50 \mathrm{HP}, 415 \mathrm{~V}$ working at 1460 rpm. The previous system used star delta starter for motor and belt pulley for power transmission to fan; due to which the blower fan kept working continuously at constant speed and at full speed regardless of the fumes generated or not. The author made a note of their observations and suggested a better way to use the energy flow. The present system has AC electronic speed variable drive and software designed according to the drive operation to optimize the power consumption during idling of mill. The new system after implementation has smooth start which increases life of motor and energy saving due to speed/ voltage variation during idling mill. The monetary saving per year was calculated to be Rs. 3,60,000 with one time investment of Rs. 1,50,000.

Manoj Kumar Lamba and Abhishek Sanghi [2] conducted an energy audit on academic building with the objective of inspection and analysis of energy flow in the said building. In their work they have discussed about possible ways to conserve energy by utilizing it effectively and potential of energy savings with importance of implementing energy saving methods. The methodology used for this audit consisted of- data collection, data analysis and recommendation. It was 


\section{International Journal of Innovations in Engineering and Science, www.ijies.net}

found out that among all the electrical loads, lightning load and personal computer has the highest consumption consisting of $36 \%$ and $44 \%$ respectively. The energy saving calculations was done to find how much energy can be saved by replacing appliances with more energy efficient components. Investment cost and capital cost recovery time (payback period) was also calculated for each recommendations. It was found out that by replacing all 12,465 conventional ballast (choke) FTL in the campus with electronic ballast (choke) FTL can save $311126.4 \mathrm{kWh}$ per year. Monetary saving of Rs. 2,644,574.4 per year can be achieved by an investment of Rs. 1869750 with a payback period of 0.7 year. Also replacing CRT monitors with LCD monitors, replacing geysers with solar water heating system and use of motion sensors in corridors and toilets to automatically switch off lights if there are no movements are amongst the other recommendations suggested in this paper.

Ramya.L.N and M.A.Femina [3] in their paper about energy auditing of an educational institute, focuses on the importance of auditing by considering conventional lighting load and replacing with energy efficient lamps and comparing the results. Their paper highlights the fact that most of energy is wasted than consumed in lighting load. Lightning load consumes more than $20 \%$ of the total energy in any facility. By replacing regular tube light with CFL or LED can bring tremendous amount of energy conservation and cost savings. The building in discussion has 350 lamps of $40 \mathrm{~W}$ consuming around $2464 \mathrm{kWh} / \mathrm{month}$ in total. The $40 \mathrm{~W}$ florescent tubes can be replaced with $12 \mathrm{~W}$ CFL or $5 \mathrm{~W}$ LED for equivalent amount of illumination without any effect on consumers need. If the tube lights are replaced with CFL, the energy consumption will reduce to $739.2 \mathrm{kWh} /$ month. If replaced with LED, the energy consumption will reduce to $308 \mathrm{kWh} /$ month. Cost of energy consumed by tube lights is Rs. 12320 per month but if replaced with CFL or LED it will be around Rs. 3696 and Rs. 1540 per month respectively. The payback period of CFL and LED was calculated to be 5.2 months and 8.1 months respectively. Other recommendations such as well-litairy classrooms with insulated ceiling, switching off unnecessary electrical appliances, setting timers for AC units, using computers at optimum brightness level which is 15 to $30 \%$ and using automated sensor based lights and fans were suggested.

Sachin P. Parthe and Santosh Kompeli [4] conducted energy audit on an industry named "Kohler Power India" Aurangabad. The Kohler Company is a manufacturing company based in Kohler, Wisconsin founded in 1873. Eventough the company is best known for its plumbing products, it also manufactures engines, furniture, tile, generators and cabinetry. In this paper, they have conducted preliminary energy audit of Kohler plant, Aurangabad and energy saving ideas was observed. The company was using $250 \mathrm{~W}$ sodium vapor lamps as flood lights in shop floor. Replacing the conventional lamps with LED lamps of equivalent illumination was suggested. Net saving per year per lamp was calculated to be Rs. 5832 with payback period of 1.4 year per lamp. The total power saving on 240 nos Sodium vapor lamp lightning lamps was found out to be 43.2 KW. The next energy saving opportunity was found in blowers. The use of VFD- Variable Frequency Drive was suggested to reduce electric power consumption. By implementing VFD, the company can save $4069 \mathrm{kWh}$ units per month. It was also observed that conventional blowers were used to provide cool air for maintaining dust free environment in engine assembly section. The most effective way to reduce energy consumption here is to convert these blowers to advance breeze air blower. By changing the existing conventional blower system to advance breeze air system, cost saving of Rs. 10653 and unit saving of 78 $\mathrm{kWh}$ units per month was calculated in this paper. Average total power consumption of plant was reduced by $20 \%$ than existing consumption with the help of this energy audit.

Gousia Sultana and Harsha.H.U [5] in their paper describe the energy audit performed at Nandi Institute of Technology and Management Sciences (NIT\&MS), Bangalore in Karnataka, India. The objective of the project was to investigate the energy consumption of the campus due to fact that the electricity bill of the campus had crossed Rs. 1.90 lakh in the previous year of the energy audit. It was aimed to obtain detailed data of the energy consuming activities and evaluate the possible energy saving opportunities. The target was to achieve energy saving to an extent of $20 \%$ to $60 \%$. Accordingly, exhaustive data was collected by observation, measurements and interviewing key persons in the preliminary data collection phase. The data collected was analyzed in detail. On the basis of result of data analysis, some steps to reduce power consumption were taken. Replacement of conventional choke of all Tubular Fluorescent Lamp (TFL) by electronic choke, use of motion sensors in corridors and toilets, avoid using photocopier machine when not in use, replacing all FTL by LED lights of equal output, changing all laser printers by ink-jet printers and replacing CRT monitors of computers with LCD monitors were the 
Vol. 6, No. 4, 2021, PP. 18 -21

International Journal of Innovations in Engineering and Science, www.ijies.net

recommendations for energy saving. The total investment of required would be Rs. 2,42,062. After detailed auditing it was observed that by implementing the recommendations, there will be a reduction of about $41.66 \%$ of energy and $30.6 \%$ of cost reduction and the payback period for various appliances were calculated.

\section{V- CONCLUSION}

From the overall literature review, it is concluded that areas of energy saving and management can be found out by implementing energy audit. Hence there is a need to prefer energy auditing in all the sectors once a year. Energy audit can lead to find energy saving potential and gives recommendation on how exactly energy can be saved. By implementing energy auditing we can conserve energy, which in turn will reduce power demand in our country. The government can save a lot of money from the utility bill of bus stand building by implementing energy saving procedures.

\section{REFERENCES}

[1] Anupama Gupta, Pallavi Verma, Richa Priyadarshan "A Review on Energy Management and Audit' International Journal of Advanced Research in Electrical, Electronics and Instrumentation Engineering Vol. 4, Issue 2, February 2015.

[2] Manoj Kumar Lamba, Abhishek Sanghi "Energy Audit on Academic Building'” International Journal of Engineering Research and General Science Volume 3, Issue 4, JulyAugust, 2015

[3] Ramya.L.N, M.A.Femina "Energy Auditing - A WalkThrough Survey" International Journal of Advanced Research in Electrical, Electronics and Instrumentation Engineering, Vol. 3, Special Issue 2, April 2014.

[4] Sachin P. Parthe, Santosh Kompeli "Energy Audit and Conservation Tool for Energy Efficiency" International Research Journal of Engineering and Technology (IRJET) Volume: 02 Issue: 08 | Nov-2015.

[5] Gousia Sultana, Harsha.H.U "Electrical Energy Audit a Case Study' IOSR Journal of Electrical and Electronics Engineering (IOSR-JEEE) Volume 10, Issue 3 Ver. III (May-Jun. 2015) 